\title{
Parasit Saluran Pencernaan Sapi Bali yang Dipelihara di Tempat Pembuangan Akhir Suwung Denpasar
}

\author{
(GASTROINTESTINAL PARASITES OF BALI CATTLE MAINTAINED AT THE FINAL \\ LANDFILLS IN SUWUNG DENPASAR)
}

\section{Made Dwinata ${ }^{1 *}$, Ida Bagus Made Oka ${ }^{1}$, Nyoman Adi Suratma ${ }^{1}$, Kadek Karang Agustina ${ }^{2}$}

Laboratorium Parasitologi Veteriner, Fakultas Kedokteran Hewan Universitas Udayana, Denpasar Bali. Laboratorium Kesehatan Masyarakat Veteriner Fakultas Kedokteran Hewan

Universitas Udayana, Denpasar Bali.

*Email:dwinatadwi@yahoo.com

\begin{abstract}
ABSTRAK
Penyakit infeksi parasit pada saluran pencernaan sapi dapat menimbulkan kerugian ekonomi yang cukup tinggi karena parasit dan ternak saling berkompetisi memperebutkan zat makanan, merusak organ, menurunkan produktivitas dan menyebabkan kematian pada ternak. Penelitian ini bertujuan untuk menentukan prevalensi dan mengidentifikasi parasit saluran pencernaan pada sapi bali yang dipelihara di Tempat Pembuangan akhir (TPA) Suwung, Denpasar. Jumlah sampel yang diteliti sebanyak 100 feses sapi yang diperiksa menggunakan metode sedimentasi dan pengapungan. Hasil penelitian didapatkan prevalensi infeksi parasit saluran pencernaan pada sapi bali yang dipelihara di TPA Suwung Denpasar sebesar $65 \%$. Jenis parasit yang menginfeksi adalah type strongyl $50 \%$, Trichuris sp. $11 \%$, Strongyloides papilosus $4 \%$, Toxocara vitolorum $3 \%$, Fasciola gigantika $5 \%$, Paramphistomum sp. $11 \%$ dan Eimeria sp. $7 \%$.
\end{abstract}

Kata kunci: Prevalensi; parasit; sapi bali; TPA Suwung

\begin{abstract}
Infectious parasitic diseases gastrointestinal parasites in cattle can cause high economic losses due to parasites and livestock compete for mutual fighting nutrients, damage to internal organs, decreasing productivity and mortality in cattle. This study aimed to determine the prevalence and identifying the digestive tract parasites of bali cattle reared in the final landfills Suwung, Denpasar. The number of samples was examined as many as 100 cattle feces were examined using sedimentation and floatation methods. The result showed that the prevalence of digestive tract parasitic infection in bali cattle were maintained at the final landfills in Suwung Denpasar by 65\%. Types of infecting parasites were strongyl type 50\%, Trichuris sp. 11\%, Strongyloides papilosus 4\%, Toxocara Vitolorum 3\%, Fasciola gigantika 5\%, Paramphistomum sp. $11 \%$ and Eimeria sp. $7 \%$.
\end{abstract}

Keywords: Prevalence; parasite; bali cattle; final landfills Suwung

\section{PENDAHULUAN}

Sapi bali merupakan salah satu sapi lokal yang banyak dikembangkan di Indonesia karena banyak mempunyai keunggulan, diantaranya memiliki efisiensi reproduksi tinggi, cepat beranak, memiliki potensi sangat baik dalam menghasilkan daging. Disamping itu sapi bali juga memiliki daya adaptasi yang baik terhadap lingkungan baru (Antara dan Sweken, 2012).

Salah satu faktor yang menghambat pertumbuhan populasi ternak sapi adalah rendahnya produktivitas akibat infeksi penyakit yang berdampak pada pertumbuhan dan reproduksi. Penyakit parasit cacing saluran pencernaan merupakan penyakit yang bersifat sub klinis dan kronis yang dapat menurunkan produktivitas sapi (Agustina et al., 2013). Dampaknya dapat menimbulkan kerugian ekonomi karena kekurusan, terlambatnya pertumbuhan, gangguan metabolisme dan turunnya daya tahan tubuh (Stromberg et al., 2012) Parasit saluran pencernaan yang sering menginfeksi sapi adalah cacing 
Haemonchus contortus, Bunostomum Phlebotomum, Trichistrongylus axei, Nematodirus sp., Strongyloides papillosus Oesophagostomum radiatum, Toxocara vitoulorum, Fasciola gigantika, Pharamphistomum spp. dan jenis protozoa coccidian sp. (Taylor et al., 2007 dan Zajac et al. 2012). Tingginya kejadian suatu penyakit perasit dipengaruhi oleh hospes, parasit, lingkungan (Regasa et al., 2006)

Beberapa penelitian parasit saluran pencernaan telah dilaporkan Dwinata et al. (2009) pada sapi di Kelompok ternak Kerta Nandini Kabupaten Badung ditemukan $87 \%$ sapi yang dipelihara terinfeksi oleh cacing. Di India (Huang et al., 2014) prevalensi cacing 86,9\% dan ditemukan Eimeria sp (11,8\%). Faktor management pemeliharaan merupakan faktor yang paling dominan mempengaruhi kejadian infeksi parasit. Dengan kondisi seperti ini penanggulangan penyakit parasit tidak menjadi perhatian peternak sehingga dapat menghambat produktivitas ternak sapi yang disebabkan adanya penyakit parasit seperti cacingan atau infeksi protozoa (Agustina et al., 2016; Agustina et al., 2017).

Tempat Pembuangan Akhir (TPA) Suwung Denpasar yang fungsi utamanya sebagai tempat pembuangan akhir sampah dari hampir seluruh wilayah di kota Denpasar kini banyak dialih fungsikan oleh masyarakat sebagai tempat memelihara ternak. Manajemen peternakan sapi bali yang ditemukan di lokasi TPA Suwung ini sangat jauh berbeda dengan manajemen pemeliharaan sapi bali yang dikandangkan dan dipelihara secara baik. Sapi bali yang dipelihara di TPA Suwung tidak dikandangkan, tidak dimandikan, pakannya sebagian besar hanya berupa limbah dapur, limbah sayur dan limbah buah - buahan. Pakan utamanya adalah sampah - sampah yang ada di areal TPA Suwung. Managemen pemeliharan seperti ini yang kurang memperhatikan kebersihan, sumber pakan yang kotor dan dapat tercemar telur, larva cacing maupun ookista dari protozoa merupakan peluang yang besar dari ternak sapi bali terinfeksi oleh parasit.
Dari uraian diatas maka untuk mengurangi dampak yang ditimbulkan oleh penyakit parasit saluran pencernaan pada sapi bali, maka sangat penting sekali diperlukan data dasar tentang jenis parasit yang menginfeksi sapi bali di TPA sehingga informasi ini digunakan dalam strategi pengendalian parasit dalam upaya meningkatkan produktivitas ternak sapi bali sehingga nantinya dapat meningkatkan pendapatan peternak.

\section{MATERI DAN METODE}

\section{Sampel}

Sampel yang digunakan adalah feses segar yang diambil dari 100 ekor sapi bali yang dipelihara di Tempat Pembuangan Akhir (TPA) suwung, Denpasar. Feses dimasukan kedalam pot plastik. Pada setiap pot plastik ditempelkan nomor sampel, jenis kelamin dan umur sapi (pedet atau dewasa) sehingga tidak terjadi kekeliruan dalam pemeriksaan.

\section{Pemeriksaan feses}

\section{Metode konsentrasi sedimentasi}

Feses sapi bali dimasukkan kedalam gelas plastik yang berisi air, kemudian dihomogenkan. Selanjutnya disaring dan filtratnya ditampung dengan glass beker. Filtratnya dimasukan ke tabung sentrifius sebanyak $10 \mathrm{ml}$, kemudian disentrifius dengan kecepatan $1500 \mathrm{rpm}$ selama tiga menit. Setelah dilakukan sentrifius, supernatannya dibuang dan endapan yang tersisa ditambahkan NAOH $10 \%$ sebanyak tiga tetes, kemudian dihomogenkan dengan ditambahkan air sampai $10 \mathrm{ml}$. selanjutnya disentrifius selama tiga menit dengan kecepatan $1500 \mathrm{rpm}$. Supernatan dibuang dan endapan ditetesi dengan methylene blue $0,5 \%$ sebanyak $1-2$ tetes dan diperiksa dibawah mikroskop (Zajac et al., 2012; Suryastini et al., 2012)

\section{Metode Pengapungan}

Feses sebanyak tiga gram dimasukkan kedalam gelas plastik yang berisi air, kemudian dihomogenkan. Selanjutnya disaring dan filtratnya ditampung dengan 
glass beker. Filtratnya dimasukan ke tabung sentrifius sebanyak $10 \mathrm{ml}$, kemudian disentrifius dengan kecepatan 1500 rpm selama tiga menit. Setelah dilakukan sentrifius, supernatan dibuang dan endapan yang tersisa ditambahkan larutan pengapung sebanyak $10 \mathrm{ml}$ dan dihomogenkan. selanjutnya disentrifius selama tiga menit dengan kecepatan 1500 rpm. Tabung sentrifuse dikeluarkan dari sentrifugator dan selanjutnya ditaruh pada rak tabung reaksi pada posisi tegak lurus. tambahkan cairan pengapung perlahan sampai permukaan cairan cembung. Tunggu sekitar tiga menit kemudian ambil gelas penutup, kemudian sentuhkan pada permukaan cairan pengapung dan setelah itu ditempelkan pada gelas objek dan periksa dibawah mikroskop pembesaran obyektif 40 kali. Identifikasi telur, tropozoit protozoa dan ookista berdasarkan morfologi dan morfometri menurut (Taylor et al., 2007 dan Zajac et al., 2012)

\section{Analisis Data}

Data jenis telur cacing, ookista protozoa yang ditemukan dianalisis dan disajikan secara deskritif.

\section{HASIL DAN PEMBAHASAN}

Dari hasil pemeriksaan 100 sampel feses sapi bali yang dipelihara di TPA Suwung Denpasar didapatkan $65 \%$ (65/100) terinfeksi parasit saluran pencernaan, yang terdiri cacing klas nematoda, trematoda dan protozoa. Prevalensi infeksi cacing nematoda type strongyl 50\%, Trichuris sp. $11 \%$, Strongyloides papilosus $4 \%$ dan Toxocara Vitolorum 3\%. Prevalensi cacing trematoda sebesar 16\% yang terdiri dari Fasciola gigantika 5\% dan Paramphistomum sp. sebesar $11 \%$. Sedangkan protozoa saluran pencernaan yang ditemukan hanya dari genus Eimeria sp. sebesar 7\% (Tabel 1).

Tabel 1. Prevalensi Infeksi parasit Saluran Pencernaan pada Sapi Bali yang Dipelihara di TPA Suwung Denpasar.

\begin{tabular}{lrcc}
\hline Jenis parasit & Positif & Negatif & Prevalensi (\%) \\
\hline Type strongyl & 50 & 50 & 50 \\
Trichuris sp. & 11 & 89 & 11 \\
Strongyloides papilosus & 4 & 96 & 4 \\
Toxocara vitolorum & 4 & 96 & 4 \\
Fasciola gigantika & 5 & 95 & 5 \\
Paramphistomum sp & 11 & 89 & 11 \\
Eimeria sp. & 7 & 93 & 7 \\
\hline
\end{tabular}

Tabel 2. Prevalensi Infeksi parasit Saluran Pencernaan pada Sapi Bali yang Dipelihara di TPA Suwung Denpasar Berdasarkan Jenis Kelamin dan Umur Sapi Bali.

\begin{tabular}{lcccc}
\hline Jenis Cacing & \multicolumn{4}{c}{ Prevalensi (\%) } \\
\cline { 2 - 5 } & Jantan $(\mathrm{n}=22)$ & Betina $(\mathrm{n}=78)$ & Pedet $(\mathrm{n}=18)$ & Dewasa $(\mathrm{n}=82)$ \\
\hline Nematoda & & & & \\
$\quad$ Type strongyl & 54,5 & 48,7 & 38.9 & 52,4 \\
$\quad$ Trichuris sp. & 13,6 & 10,1 & 5,6 & 12,2 \\
$\quad$ Strongyloides sp. & 4,5 & 3,8 & 5,6 & 3,7 \\
$\quad$ Toxocara vitolurum & 9,1 & 2,6 & 16,7 & 1,2 \\
Trematoda & & & & \\
$\quad$ Fasciola gigantika & 4,5 & 5,1 & 5,6 & 4,8 \\
$\quad$ Paramphistomum sp. & 13,6 & 10,2 & 4,9 & 11 \\
Protozoa & & & & 6,1 \\
$\quad$ Eimeria sp. & 9,1 & 6,4 & 11,1 & \\
\hline
\end{tabular}


Prevalensi infeksi cacing saluran percernaan berdasarkan jenis kelamin sapi bali pada sapi jantan ditemukan cacing type strongyl, Trichuris sp., Strongyloides papilosus, Toxocara vitolorum, Fasciola gigantika, Paramphistomum sp. dan protozoa Eimeria sp. berturut-turut sebesar $54,5 \%, 13,6 \%, 4,5 \%, 9,1 \%, 4,5 \%, 13,6 \%$ dan $9,1 \%$. Sedangkan pada sapi betina $48,7 \%, 10,3 \%, 3,8 \%, 2,6 \%, 5,12 \%, 10,2 \%$ dan $6,4 \%$. Prevalensi parasit saluran pencernaan pada pedet ditemukan cacing type strongyl, Trichuris sp., Strongyloides papilosus, Toxocara vitolorum, Fasciola gigantika, Paramphistomum sp. dan protozoa Eimeria sp. berturut-turut sebesar $38,9 \%, 5,6 \%, 5,6 \%, 16,7 \%, 5,6 \%, 4,9 \%$ dan $11,1 \%$. Prevalensi sapi bali dewasa $52,4 \%, 12,2 \%, 3,7 \%, 1,2 \%, 4,8 \%, 11 \%$ dan $6,1 \%$ seperti pada Tabel 2 .

Hasil penelitian ini ditemukan prevalensi parasit saluran pencernaan pada sapi bali sebesar $65 \%$ yang terdiri dari cacing nematoda, trematoda dan protozoa. Faktor management pemeliharaan merupakan faktor yang paling dominan mempengaruhi kejadian infeksi parasit. Managemen pemeliharaan yang kurang baik dapat menghambat produktivitas ternak sapi karena adanya infeksi cacing. Tempat Pembuangan Akhir (TPA) Suwung Denpasar yang fungsi utamanya sebagai tempat pembuangan sampah akhir yang berasal dari hampir seluruh wilayah di kota Denpasar, kini banyak dialih fungsikan oleh masyarakat sebagai tempat memelihara ternak. Sapi dipelihara dilepas mencari pakan berupa hijauan, sisa makanan, minuman, yang didapatkan dari tumpukan sampah yang ada di TPA (Putra et al., 2018). Kondisi kebersihan kurang terjaga dengan banyaknya kotoran sapi yang ditemukan di sepanjang jalan dapat mencemari pakan sapi sehingga dapat merupakan sumber penularan pada sapi yang dilepas disana (Ardanti et al., 2016). Cara pemeliharaan seperti ini dapat memicu terjadinya infeksi cacing maupun protozoa akibat dari makanan dan minuman tercemar oleh telur, larva dan ookista infektif. Tingginya prevalensi parasit juga dipengaruhi oleh musim, dimana penelitian dilakukan pada saat musim hujan sehingga mendukung perkembangan siput sebagai hospes intermidier dari cacing Fasciola $s p$. dan Paramphistomum sp. Tempratur dan kelembaban yang optimum pada musim hujan mendukung perkembangan dan migrasi larva parasit dan perkembangan stadium infektif pada siput (Sardar et al., 2006).

Jenis cacing nematoda type strongyl yang paling dominan ditemukan pada penelitian ini (50\%) sesuai dengan dilaporkan peneliti yang lain (Haque et.al., 2011; Rahman et al., 2012; Huang et al., 2014). Di Kenya (Kabaka et al., 2013) melaporkan jenis cacing type strongyl yang menginfeksi sapi adalah Haemonchus contortus 28,5\%, Trichostrongylus sp. $19,5 \%$ dan oesophagostomum sp. 14,8\%. Tingginya prevalensi cacing tipe strongyl disebabkan kondisi lingkungan pada tempat pemeliharaan sapi yang mendukung perkembangan telur dan larva cacing, nutrisi yang kurang dan pemberian obat cacing yang jarang dilakukan (Williams and Loyacano, 2001; Boomker, 2015).

Beberapa hasil penelitian tentang parasit saluran pencernaan pada sapi telah dilakukan. Di India, dilaporkan infeksi parasit saluran pencernaan pada sapi sebesar $28,25 \%$ yang terdiri dari type strongyl 65,89\%, Strongyloides sp. 25,13 $\%$, Eimeria spp. 17,8\%, Trichuris spp. 13,08\%, Moneizia sp, $10,47 \%$ dan Nematodirrus spp. 2, 61\% (Laha et al., 2013). Di Ethiopia dilaporkan prevalensi cacing nematoda saluran pencernaan yaitu Ascaris sp. 2.8\%, Strongyloides papillosus 47\%, Trichuris spp. 1,6\% (Regassa et al., 2006). Di Taiwan (Huang et al., 2014) menemukan prevalensi parasit saluran cerna pada sapi sebesar $86,9 \%$ dengan angka infeksi pada protozoa, nematoda, trematoda dan cestoda sebesar $81,3 \%$, $7,9 \%, 1,6 \%$ dan $0,6 \%$. Jenis protozoa yang dilaporkan Cryptosporodium spp. 32,6\% dan Eimeria spp. 11,8\%. Adanya variasi hasil penelitian dipengaruhi oleh bergai 
faktor seperti lingkungan yang berbeda, nutrisi, sistem managemen pemeliharan, musim, umur dan jenis sapi.

Pada penelitian ini ditemukan cacing trematoda Fasciola gigantika (5\%) dan Paramphistomum sp. (11\%), lebih rendah dibandingkan dengan hasil penelitian Putra (2015) di Kabupaten Badung sebesar 27\%. Tantri et al. (2013) juga didapatkan hasil yang lebih tinggi dimana prevalensi cacing Trematoda pada sapi di RPH Kota Pontianak Kalimantan Barat didapatkan sebesar $36,5 \%$, dengan prevalensi cacing Fasciola sp. sebesar $18,75 \%$ dan Paramphistomum sp. sebesar $17,75 \%$. Infeksi cacing trematoda terjadi melalui metaserkaria yang mencemari rumput (Zajac et al., 2012). Pada sapi yang dipelihara di TPA Suwung Denpasar selain mendapatkan makanan dari sisa limbah juga memporeh makanan dari rumput disekitar TPA sehingga dapat terinfeksi oleh cacing trematoda. Prevalensi ini juga disebabkan oleh beberapa faktor seperti: suhu, kadar oksigen dan tempat dimana pakan sapi tersebut didapatkan (Hafsah, 2013). Meningkatnya pencemaran lingkungan oleh bahan bahan kimia dapat menurunkan populasi hospes intermidier yaitu siput yang secara signifikan akan menurunkan prevalensi dari cacing trematoda (Huang et al., 2014). Selain itu banyaknya populasi siput sebagai inang antara dari cacing trematoda perkembangannya dipengaruhi oleh lingkungan yang basah dan tingkat curah hujan yang tinggi. Kejadian fascioliasis pada negara tropis ditentukan oleh curah hujan dan sisten produksi (Wadhwa et al., 2011; Kardena et al., 2017)

Hasil identifikasi protozoa saluran cerna pada sapi ditemukan Eimeria sp. (7\%). Hasil ini tidak jauh berbeda dengan hasil penelitian yang dilaporkan Widnyana (2013) di Desa Woso Kecamatan Bungku Barat Kabupaten Morawali dengan prevalensi Eimeria sp. 10\%. Di Taiwan (Huang et al., 2014) prevalensi Eimeria sp. sebesar $11,8 \%$. Sapi dapat terinfeksi oleh
Eimeria sp. melalui tertelannya ookista bersama makanan atau minuman yang terkontaminasi ookista yang telah bersporalasi (Zajac et al., 2012). Tingkat infeksi protozoa saluran cerna meningkat dapat dipengaruhi oleh kebersihan kandang yang rendah dan kondisi lingkungan yang optimum untuk perkembangan stadium ookista.

\section{SIMPULAN DAN SARAN}

\section{Simpulan}

Dari hasil penelitian dapat disimpulkan prevalensi parasit saluran pencernaan pada sapi bali yang dipelihara di TPA Suwung, Denpasar sebesar 65\%. Parasit yang didapatkan terdiri dari type strongyl 50\%, Trichuris sp. 11\%, Strongyloides papilosus 4\%, Toxocara Vitolorum 3\%, Fasciola gigantika 5\%, Paramphistomum sp. $11 \%$ dan Eimeria sp. 7\%.

\section{Saran}

Perlu penelitian lebih lanjut dampak infeksi parasit terhadap pertumbuhan sapi dan melakukan pemberian obat cacing secara teratur pada sapi bali yang dipelihara di TPA Suwung Denpasar dalam upaya meningkatkan produktivitas ternak sapi.

\section{UCAPAN TERIMAKASIH}

Penulis mengucapkan terimakasih kepada Universitas Udayana atas dana penelitian PNBP Universitas Udayana sesuai dengan Surat Perjanjian Penugasan Pelaksanaan Penelitian Nomor: 246311/UN14.2/PNL.01.03.00/2016, sehingga terlaksananya penelitian ini

\section{DAFTAR PUSTAKA}

Agustina KK, Dharmayudha AAGO, Wirata IW. 2013. Prevalensi Toxocara vitulorum Pada Induk Dan Anak Sapi Bali Di Wilayah Bali Timur. Bul. Vet. Udayana. 5(1): 1-6.

Agustina KK, Wirata IW, Dharmayudha AAGO, Kardena IM, Dharmawan NS. 2016. Increasing farmer income by improved pig management systems. Bul. Vet. Udayana. 8(2): 122-127. 
Agustina KK, Swacita IBN, Oka IBM, Dwinata IM, Traub RJ, Cargill C, Damriyasa IM. 2017. Reducing zoonotic and internal parasite burdens in pigs using a pig confinement system. Vet. World. 10(11): 1347-1352.

Al-shaibani IRM, Phulan MS, Arijo A, Qureshi TA. 2008. Contamination of Infective larvae of Sheep on Communal Pasture. Int. J. Agric. Biol. 10: 657.

Ardanti TIAS, Yupardhi WS, Ariana INT. 2016. Profil darah dan tingkat kerusakan hati pada sapi bali yang digembalakan di tempat pemerosesan akhir Suwung Denpasar. Majalah Ilmiah Peternakan. 19(1): 12-17.

Boomker J. 2015. Helminth infections of ruminants. Univ. of Pertoria. Pp: 1-46.

Dwinata I M, Oka IBM dan Damriyasa IM. 2009. Pemberantasan Penyakit Parasiter Berbasis Pemeriksaan Koproskopis pada Kelompok Ternak Sapi Kerta Nandini Desa Petang. Laporan Pengabdian Penerapan Iptek

Hafsah. 2013. Karakteristik habitat dan morfologi siput ongcomelania hupensis lindoensis sebagai hewan reservoir dalam penularan shistosomiasis pada manusia dan ternak di taman nasional lore lindu. J. Manusia dan Lingkungan. 20(2): 144-152.

Huang CC, Wang LC, Pan CH, Yang CH, Lai CH. 2014. Investigation of gastrointestinal parasites of dairy cattle around Taiwan. J. Microbiol. Immunol. Infec. 47: 70-74.

Kabaka WM, Gitaub GK, Kitalaa PM, Maingic N and Van Leeuwen JA. 2013. The prevalence of gastrointestinal nematode infection and their impact on cattle in Nakuru and Mukurweini districts of Kenya. Ethiop. Vet. J. 17(1): 95-104.

Kardena IM, Winaya IBO, Adi AAAM, Berata IK, Adnyana IBW, Sukada IM, Agustina KK, Antara PATK. 2017. Patological changes in liver and gall bladder of bali cattle infected by fasciolosis. J. Vet. Med. Anim. Sci. 1(1): 6-10.
Laha R, Das M, Goswami A. 2013. Gastrointestinal parasitic infections in organized cattle farms of Meghalaya. Vet. World. 2013: 109-112.

Marie GBA, Prosper OO, Bensin R. 2001. Gastro-intestinal nematodas and Cestodes of cattle in Burkina Faso. Biotechnol. Agron. Soc. Environ. 5(1): 17-21.

Moyo DZ. 2006. An Abbatoir study of Prevalence and seasonal Fluctutions of gastrointestinal nematodes of cattle in the Midlands Province, Zimbabwe. Res. J. Anim. Vet. Sci. 1(1): 37-40.

Putra WS, Berata IK, Kardena IM. 2018. Kadar logam berat $\mathrm{Pb}$ dan histopatologi limpa sapi bali yang dipelihara di tempat pembuangan akhir Suwung Denpasar. Bul. Vet. Udayana. 10(1): 64-69.

Rajakaruna, Warnakulasooriya. 2011. Gastrointestinal parasites in dairy cattle in Kandy District in Srilangka. Ann. Res. J. 11: 92-99.

Rahman H, Pal P, Bandyopadhyay B, Chalod LR. 2012. Epidemiology of gastrointestinal parasitism in cattle in Sikkim. Indian J. Anim. Sci. 82: 151153.

Regassa F, Sori T, Dhuguma R, Kiros Y. 2006. Epidemiology of gastrointestinal parasites of ruminant in Western Oromia, Ethiopia. Intern. J. Appl. Res. Vet. Med. 4(1): 51-57.

Sardar SA, Ehsan MA, Anower AKMM, Rahman MM and Islam MA. 2006. Incidece of Liver Fluke and GastroIntestinal Parasite in Cattle. Bangl. $J$. Vet. Med. 4(1): 39-42.

Stromberg BE, Gasbarre LC, Waite A, Bechtol DT, Brown MS, Robinson NA, Olson EJ. 2012. Newcomb. Cooperia punctate, effect on cattle productivity? Vet. Parasitol. 183: 284-291.

Suryastini, KAD., Dwinata, IM., Damriyasa, IM. 2012. Akurasi Metode Ritchie Dalam Mendeteksi Infeksi Cacing Saluran Pencernaan Pada Babi. Indon. Med. Vet. 1(5): 567-581. 
Taylor MA, Coop RL, Wall RL. 2007. Veterinary Parasitology. Blackwell Publishing, Oxford, UK.

Tantri N, Setyawati TR, Khotimah S. 2013. Prevalensi dan itensitas telur cacing parasit pada feses sapi (Bos sp.) Rumah Potong Hewan (RPH) Kota Pontianak Kalimantan Barat. Protobiont. 2(2): 102-106.

Zajac AM. 2012. Clinical Veterinary Parasitology. $8^{\text {th }} \quad$ Ed. Blackweii Publishing. Iowa.

Wadhwa A, Tanwar RK, Singla LD, Eda S, Kumar N, Kumar Y. 2011. Prevalence of Gastrointestinal Helminthes in Cattle and Buffaloes in Bikaner, Rajasthan, India. Vet. World. 4(9): 417-419.

Widnyana IGNP. 2013. Prevalensi Infeksi Parasit Cacing pada Saluran Pencernaan Sapi Bali dan sapi Rambon di Desa Wosu Kecamatan Bungku Barat Kabupaten Morowali. J. Agro. Pet. 10(2): 1-8.

Williams JC, Loyacano AF. 2001. Internal parasites of cattle in Louisiana and other Southern States. Res. Inform. Sheet. 104: 1-20. 